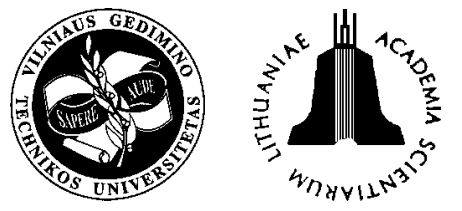

ISSN 1648-4142 TRANSPORT

http:/www.vtu.lt/english/editions

TRANSPORT - 2004, Vol XIX, No 5, 214-218

\title{
THE ANALOGY METHOD FOR THE DESCRIPTION OF EXTERNAL CHARACTERISTIC OF INNER COMBUSTION ENGINES
}

\author{
Agnius Stonys, Jonas Sapragonas, Saulius Mockus \\ Dept of Transport Engineering, Kaunas University of Technology, Kęstučio g. 27, \\ LT-44025 Kaunas, Lithuania. Tel. (8-37)323788
}

Received 2004-02-12; accepted 2004-06-30

\begin{abstract}
The original data for the evaluation of vehicle motion dynamics is external characteristic of its engine, which consists of three parameters: torque, power and specific fuel consumption. It is very important to have the dependences of these characteristics on revs for various engine load cases, creating a vehicle model under real motion conditions. Load cases are defined by a load coefficient. Car-makers usually don't declare full engine external characteristics, which overtake all load coefficient variation interval. The purpose of this article is to research, how to get full description of engine torque function without its full data. The analogy method, which is used in polymers and composites mechanics, was employed for the description of a torque function. The method is based on the creation of summarized characteristic, making horizontal and vertical shifts of torque dependences. From the curve it is possible to get a proper characteristic at a chosen load coefficient.
\end{abstract}

Keywords: external characteristic of inner combustion engine, vehicle dynamics, torque function, load coefficient, analogy method, summarized characteristic.

\section{Introduction}

The external characteristic of an inner combustion engine is necessary for vehicle dynamic researches under various exploitation conditions. The solution of some tasks - maximum speed evaluation, maximum average speed evaluation - does not make difficulties, if other bounds are not used. However, today vehicle dynamic characteristics are not deciding, when the whole potential of an engine is used. Other factors are becoming more important: fuel consumption, traffic safety, environment pollution. Recently the solving of tasks becomes more complicated, because:

- automatic cruise control systems, are produced which not only keep set motion speed, but also react to motion environment, traffic changes;

- engine control algorithms for optimal system "engine-automatic or sequential transmission" work, are designed not only according to economic, but also to environment pollution requirements;

- tracing after leader control systems are created when vehicles train control is defined by leader's motion algorithm;

- engine optimal work control algorithms are researched with alternative fuel sorts: LPG, ethanol, methanol, various petrol and ethanol compounds;

- optimal control systems of hybrid power trains are created made of inner combustion and electric engines.

For all these cases we need external characteristic of inner combustion engine work under various regimes and forecast algorithms of engine reaction to control effect. Unfortunately publications in this range are given very few, because inner 120 combustion engine work depends on a lot of parameters. So the article is devoted to the analysis of external characteristic description methods, when inner combustion engine works under various regimes.

\section{Engine external characteristic and its mathemati- cal description}

Inner combustion engines, which are used in transport means, usually in exploitation models are described by three parameters: torque, power and specific fuel consumption. All these parameters are engine crankshaft revs functions: $M(n), N(n), g_{e}(n)$. These characteristics are set, using engine's experimental stand tests with ultimate fuel feed, i.e. when engine load is maximum. Received characteristics can be used for vehicle dynamic evaluation.

In this paper we explored torque $M(n)$ function, because it defines engine specialty more precise. Usually $M(n)$ function is described by second order poly- 
nomial [1]:

$$
M=M_{N} \cdot\left[a_{0}+a_{1} \cdot\left(\frac{n}{n_{N}}\right)-a_{2} \cdot\left(\frac{n}{n_{N}}\right)^{2}\right],
$$

here $M_{N}$ and $n_{N}$-torque and engine revs when power is maximum; $a_{b} a_{1}, a_{2}-$ stable for concrete engine coefficients.

In the vehicle model for real exploitation conditions (traffic in a city or in a country), the load of engine will be maximum just for a short time. The new criterion is necessary for making a group of engine characteristics for various load cases. In this case we will have the function of two parameters: $M(n, \beta)$. Here $\beta$ is coefficient of engine load. In petrol engines coefficient $\beta$ describes an opening angle of intake manifold valve, and in diesel engines - a position of fuel pump adjuster. Function $M(n, \beta)$ is complicated [2-4] and mathematically can be described by equations:

$$
\begin{aligned}
& M=a_{0}+a_{1} \cdot n+a_{2} \cdot n^{2}+a_{3} \cdot \beta+a_{4} \cdot n \cdot \beta+a_{5} \cdot \beta^{2},(2) \\
& M=\frac{a+b \cdot \ln (n)+c \cdot(\ln (n))^{2}+d \cdot \ln (\beta)}{1+e \cdot \ln (n)+f \cdot \ln (\beta)+g \cdot(\ln (\beta))^{2}+h \cdot(\ln (\beta))^{3}} .(3)
\end{aligned}
$$

Our researches show that for the common case this equation should be used:

$$
M=\sum_{i=1}^{k} \sum_{j=1}^{l} a_{i j} \cdot n^{i-1} \cdot \beta^{j-1} .
$$

Analyzing (4) equation practice conditions, we have set that engines must be classified according to construction and fuel sort. Besides, it is very difficult to get full $M(n)$ characteristic through all variation interval of coefficient $\beta$. So it is purposeful to divide all coefficient $b$ variation interval into three zones: working, intermediate and engine braking [3]. Using this way, accurate experimental data are necessary, when engine works under all regimes, but variation of several polynomial coefficients cannot be set, because they change radically after polynomial order change. Streamlined equation can be used only in several cases, exploring a full correlation function. Therefore we were looking for the ways to get $M(n, \beta)$ function mathematical description without full experimental data.

\section{The description of torque function}

Using classic $M(n)$ function description method [1], we have problems with modern engines torque characteristics. Characteristics are not monotonic resonant phenomena are noticeable in intake and exhaust manifolds [5]. The increase of description polynomial order doesn't give better results [3], so we decided to use a classic method for torque function description and we were trying to describe consisted deflections using Furje analysis (Fig 1). The accuracy of description was estimated by average square deflections. The results are given in Table 1 .

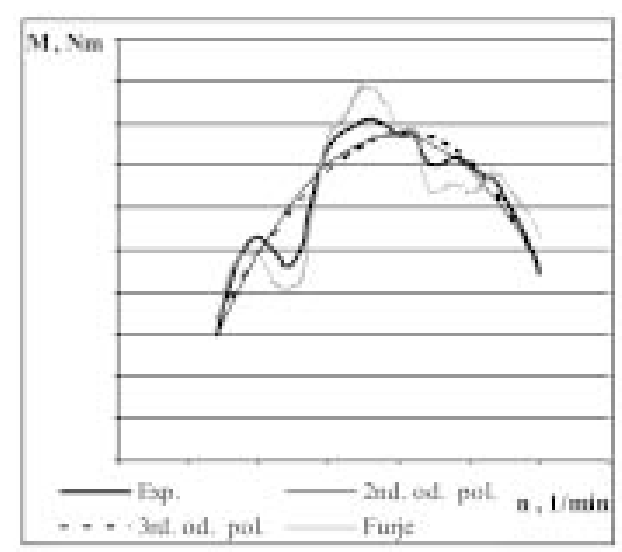

Fig 1. Torque characteristic and its descriptions

Table 1. Comparison of description methods

\begin{tabular}{|l|l|l|l|}
\hline $\begin{array}{l}\text { Description } \\
\text { method }\end{array}$ & $\begin{array}{l}\text { 2nd order } \\
\text { polynomial }\end{array}$ & $\begin{array}{l}\text { 3rd order } \\
\text { polynomial }\end{array}$ & $\begin{array}{l}\text { 2nd order } \\
\text { polynomial } \\
\text { +Furje } \\
\text { analysis }\end{array}$ \\
\hline $\begin{array}{l}\text { Total } \\
\text { comparative } \\
\text { error } \%\end{array}$ & 2,06 & 1,91 & 1,56 \\
\hline
\end{tabular}

Analyzing some engines torque characteristics with pointed influence of resonant phenomena, we noticed that in a working zone $(\beta=1 . . .0,3)$ resonant phenomena do not change and their influence can be evaluated by interpolation (Fig 2). The facts about engines work in an intermediate and engine braking

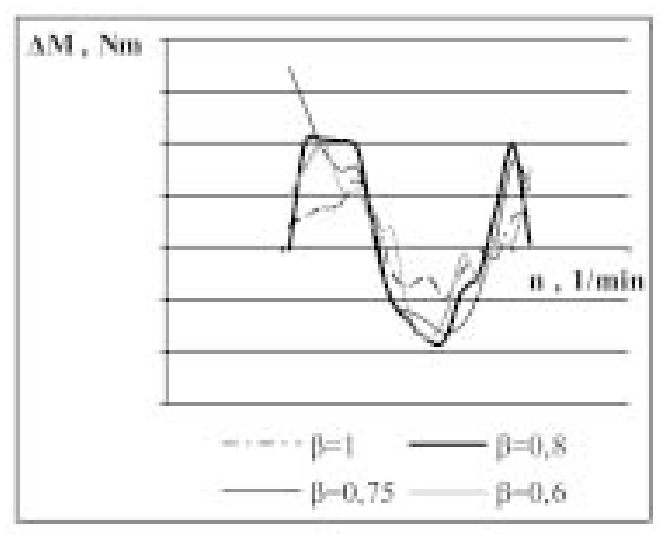

Fig 2. Deflections of torque characteristic towards different load cases 


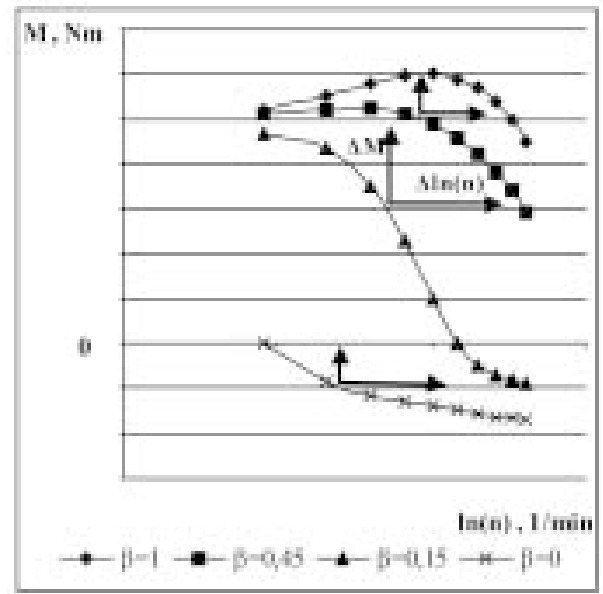

a)

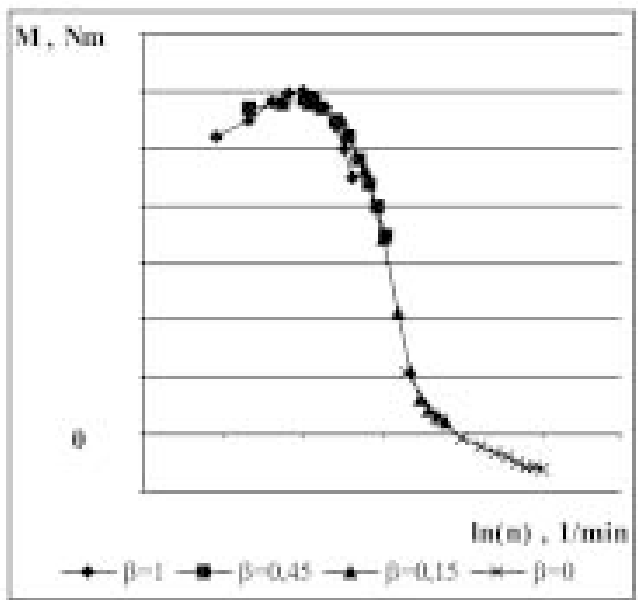

b)

Fig 3. The principle of torque characteristic summarizing: a) $M(\ln (n))$ curves towards different load coefficient $\beta$; b) summarized $M(\ln (n))$ curve

zone, where resonant phenomena are used, are given very few. So we have accepted that torque characteristic in these regimes is analogical to the characteristic of similar displacement and construction engines.

\section{Analogy method}

Analyzing the influence of load coefficient $b$ on torque characteristic and traversing changing of $M(n, b)$ function $[3,6]$, it was decided to use an analogy method for the description of the function. Such method is used in polymers and composites mechanics [7], when mechanical characteristics dependence in action time and temperature coordinates is not precisely defined and elaborated. Analogically for the methods of polymer mechanics, the influence of physical meanings on the engine external characteristic could be evaluated by resumptive parameters. The influence of fuel compound composition, combustion process, energy balance and other process changes on engine load can be considered as engine revs change, the influence of torque change - as a function vertical correction. Using the concept of modified revs $((\ln (n))$ and making $M(\ln (n))$ curves horizontal and vertical shifts towards different coefficient $b$, it is possible to get a summarized torque characteristic (Fig 3).

Different damage influence on torque is estimated, shifting $M((\ln (n))$ curves vertically, analogically to thermoreologicaly complex polymeric materials [7]. Values of vertical shifts are determined using horizontal shifts values - in optimal case values of horizontal shifts depend only on load coefficient $b$ and don't depend on engine revs $\ln (n)$. Besides, $M(\ln (n))$ curves, adjusted in different regimes, have to overlay at least by two thirds.
It is impossible to formalize summarized $M(\ln (n)$ curve, using second or third order polynomials, so we returned to the method offered in the work [3] - to divide the whole coefficient $b$ variation interval into three zones: working, intermediate and engine braking. Analyzing braking characteristics $[5,6]$, we noticed, that the use of the analogy method for their description is completely answering the purpose, and summarized characteristic can be designed making elementary shifts in logarithmic coordinates without vertical correction. That's why we pay more attention to regime formalization analysis.

\section{Description of an experimental torque character- istic using the analogy method}

The experimental research was developed on WV RP 1,8 1 engine from WV Passat. The main data of this engine are given in Table 2 . The $M(\ln (n), \beta)$ characteristic is given in Fig 4.

Table 2. WV Passat technical data

\begin{tabular}{|c|c|}
\hline Cylinders/Configuration & 4/line \\
\hline Displacement, $\mathrm{cm}^{3}$ & 1781 \\
\hline Fuel system & monoinjection \\
\hline Compression & 9,0 \\
\hline Power, $\mathrm{kW} / \mathrm{min}^{-1}$ & $66 / 5400$ \\
\hline Torque, $\mathrm{Nm} / \mathrm{min}^{-1}$ & $142 / 3500$ \\
\hline Revs $(\mathrm{max}), \mathrm{min}^{-1}$ & 6300 \\
\hline
\end{tabular}

After stand tests $M(n)$ curves were got, depending on load coefficient $\beta$. We tested work zone, when load coefficient $\beta=[1 . .0,4]$, because for its variation interval test, the engine must be taken out from a ve- 


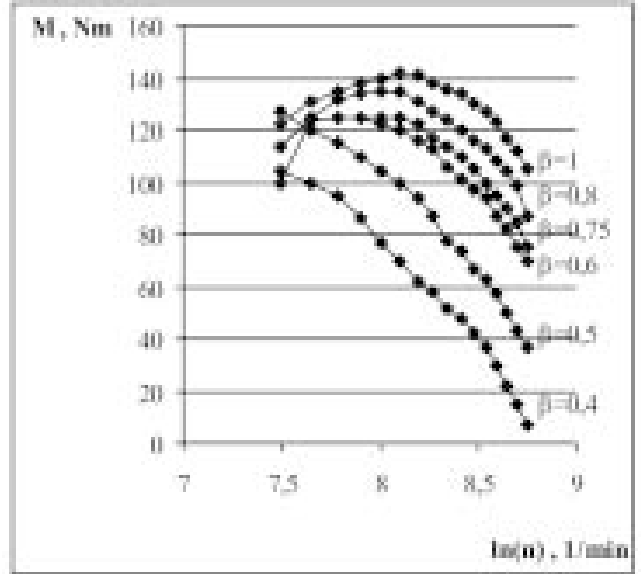

a)

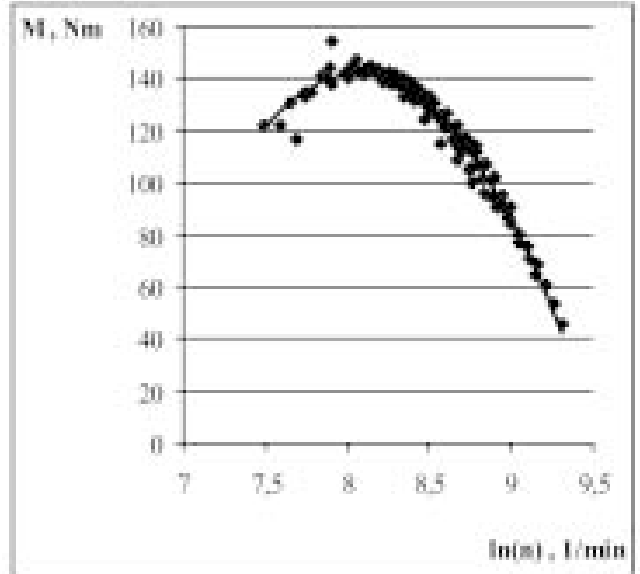

b)

Fig 4. Engine torque characteristic: a) $M(\ln (n), \beta)$; b) summarized

hicle. Besides, the extra equipment is necessary for engine load security in high revs zone, when coefficient $\beta$ becomes less than $0,3[2,5]$. Positions of intake manifold valve were chosen insomuch, that the analogy method could be used, e.i. characteristics of adjacent regimes overlaid by two thirds.

Further shifts were made, depending on coefficient $\beta: \Delta n(n)(\beta)$ (Fig 5) and $\Delta M(\beta)$ (Fig 6). The shift values were optimized by goal function - average square deflection $P(\Delta \ln (n), \Delta M)$ (Fig 7).

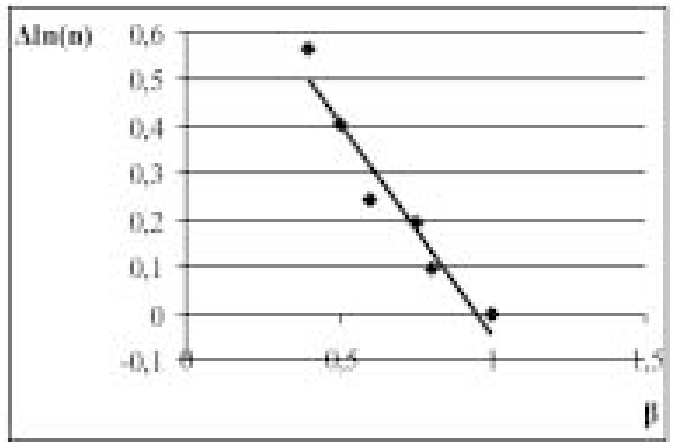

Fig 5. Shift $\Delta \ln (n)(\beta)$

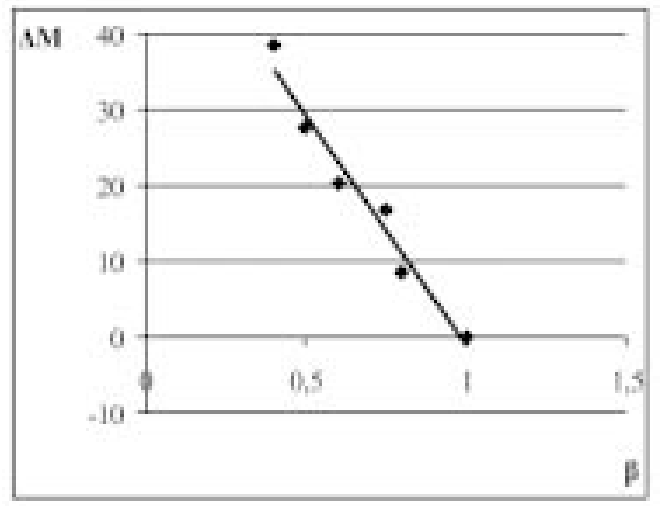

Fig 6. Shift $\Delta M(\beta)$

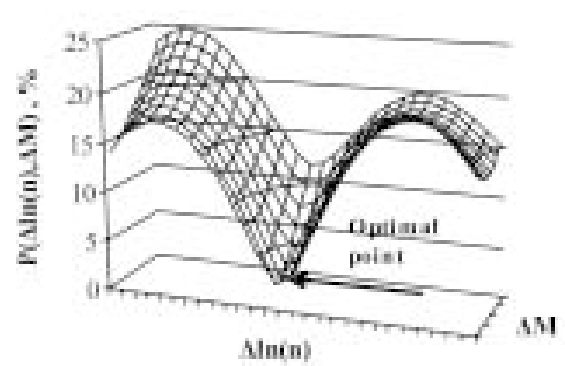

Fig 7. The goal function and optimal point

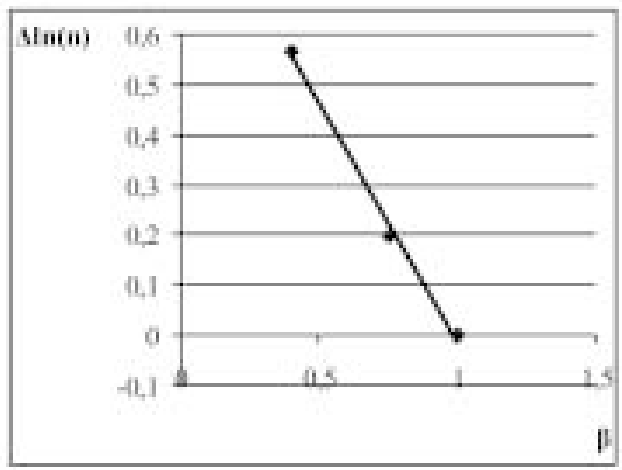

Fig 8. Shift $\Delta \ln (n)(\beta)$

Having these results, after horizontal and vertical shifts retroaction we can get $M(n)$ curve from coefficient $b$ variation interval $[1 . .0,4]$.

Calculated results were compared with experimental data. For comparison we have chosen $M(\ln (n))$ characteristics, when $\beta$ is: $1 ; 0,75 ; 0,4$. Shift $\Delta \ln (n)(\beta)$ is given in Fig 8 and $\Delta M(\beta))$ - in Fig 9 .

After the retroaction from a summarized curve, $M(\ln (n))$ curves were received, when coefficient $\beta$ is: 0,$8 ; 0,5$. The results were compared with experimental data (Fig 10). Precision of description was evaluated using formula (5). 


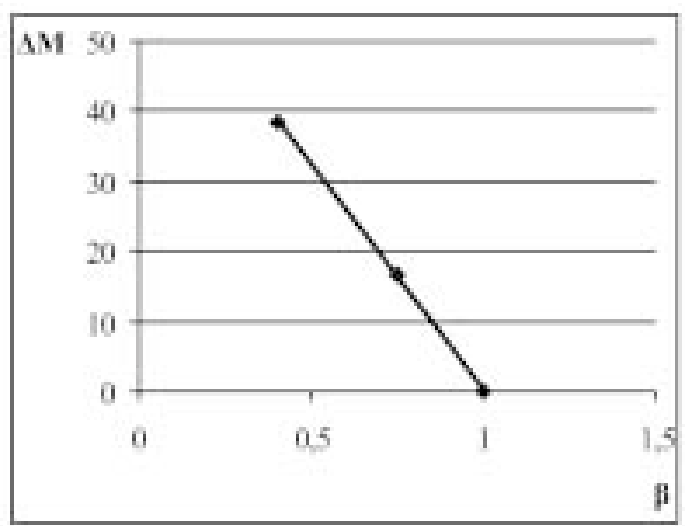

Fig 9. Shift $\Delta M(\beta)$

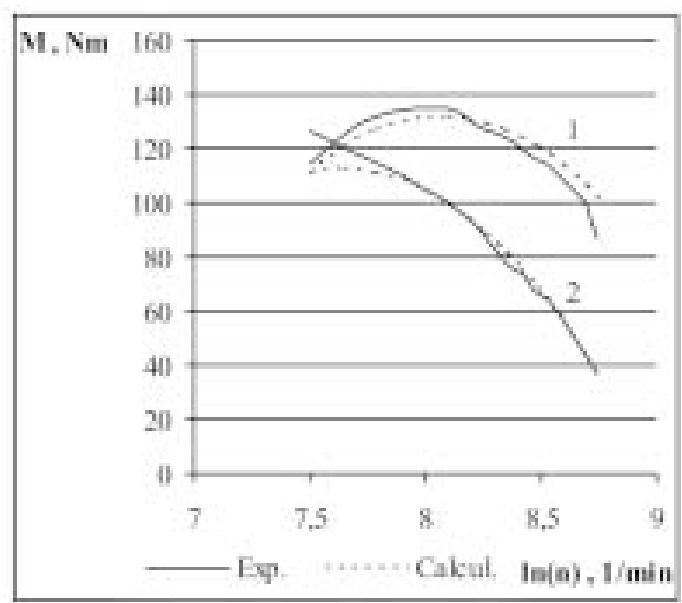

Fig 10. Comparison of calculated and experimental $M(\ln (n))$ characteristics: $1-\beta=0,8 ; 2-\beta=0,5$

$$
\Delta=\sqrt{\frac{\sum_{i=1}^{n}\left(\frac{M_{c i}-M_{\exp i}}{M_{\exp i}}\right)^{2}}{n}},
$$

here $\Delta$ - total comparative error; $M_{c i}$ - calculated torque meaning; $M_{\text {expi }}$-experimental torque meaning; $n$ - number of meanings.

\section{Conclusions}

Having the results of modeling, the following was concluded:

1. There is no universal mathematical model which would be good for external characteristics description of various inner combustion engines. Trying specifically to describe changes of $M(n)$ function towards load coefficient $\beta$, it is necessary to divide all variation interval of load coefficient into three zones: working, intermediate and braking.
2. Methods for the description of engine external characteristics towards various load cases, which were used until now, are sustained by correlation analysis. The analogy method allows displaying the main tendency of changes of external characteristic for several engine groups. In this case we can get intermediate regimes without full external characteristic.

3. The number of experimental stand tests can be reduced using the offered analogy method and bound meanings of load coefficient can be evaluated.

4. It was set that using the analogy method total comparative errors are: $5,54 \%$ when load coefficient $\beta$ is 0,8 and $4,17 \%$ when $\beta=0,5$. The method can be successfully used for comparative evaluations.

\section{References}

1. Gillespie, T. D. Fundamentals of vehicle dynamics. Warrendale: SAE 1992, D192223. 495 p.

2. Tarasik, V. P. Road Vehicles' Design (Проектирование колесных тягово-транспортных машин). Minsk: High school, 1984. 163 p. (in Russian).

3. Stonys, A.; Kisko, K. Mathematical Modeling of the External Characterization for Inner Combustion Engine. In: Proceeding of International Conference. Transport Means 2003. Kaunas, 2003, p. 144-147.

4. Serban, F.; Cristea, D.; Marinescu, D. Computational Modelling and Optimization of Power Trains. In: Symposium on computational modelling of combustion \& multiphase flows in energy systems, July, 2003, Neptun, Romania.

5. Hardie, C.; Tait, H.; Craig, S. Automated tuning of an engine management unit for an automotive engine. Automobile Engineering, Vol 216, No 8, 2002, p. 841849.

6. Silka, W. Theory of vehicle motion (Teoria ruchu samochodu). Warsaw: WNT, 2002. 330 p. (in Polish).

7. Urzumsev, U. S.; Maksimov, R. D. Prognosis of polymeric materials deformations (Прогностика деформативности полимерных материалов). Riga: Zinatne, 1975. 415 p. (in Russian). 